\title{
REPORT OF A PATIENT WITH A RING CHROMOSOME 10: $\operatorname{mos} 45, \mathrm{XY},-10 / 46, \mathrm{XY} / 46, \mathrm{XY}, \mathrm{r}(10)(\mathrm{p} 15.3 \mathrm{q} 26.3)$
}

\author{
Kunikazu KishI, ${ }^{1, *}$ Tatsuro IKfuchI, ${ }^{1}$ Kohtaro Yamamoto, ${ }^{1}$ \\ Akira Tonomura, ${ }^{1}$ Noriyuki Sakurada, ${ }^{2}$ \\ and Yoshiaki SATOH ${ }^{3}$ \\ ${ }^{1}$ Department of Cytogenetics, Medical Research Institute. Tokyo Medical \\ and Dental University, Bunkyo-ku, Tokyo 113, Japan \\ ${ }^{2}$ Department of Pediatrics, School of Medicine, Tokyo Medical and Dental \\ University, Bunkyo-ku, Tokyo 113, Japan \\ ${ }^{3}$ Department of Dermatology, School of Medicine, Tokyo Medical \\ and Dental University, Bunkyo-ku, Tokyo 113, Japan
}

\begin{abstract}
Summary A 2.5-year-old boy with a ring chromosome 10 was described. Clinical features included developmental retardation, short stature, mild mental retardation and cryptorchidism. He had a history of photohypersensitivity. By using PHA stimulated peripheral blood lymphocytes, Epstein-Barr virus transformed lymphoblastoid cell line and cultured skin fibroblasts, his karyotype was identified to be $\operatorname{mos} 45, \mathrm{XY},-10 / 46, \mathrm{XY} /$ 46,XY,r(10) (p15.3q26.3).
\end{abstract}

\section{INTRODUCTION}

Only nine patients with a ring chromosome 10 have so far been reported (Lansky et al., 1977; Fryns et al., 1978; Sparkes et al., 1978; Simoni et al., 1979; Tsukino et al., 1980; Michels et al., 1981, Serville et al., 1982; Nakai et al., 1983; Kondo et al., 1984). In this report, we present a patient with a mosaic karyotype of $45, X Y$, $-10 / 46, X Y / 46, X Y, r(10)$ (p15.3q26.3) who showed relatively mild phenotypic anomalies. The ring chromosome was analyzed in more detail by high-resolution banding.

\section{CASE REPORT}

The proband was the first child of non-consanguineous parents. He was born after an uncomplicated pregnancy of 39 weeks and a normal delivery. There was

Received July 16,1985

* Correspondence and reprint requests should be addressed to the following: Department of Adult Health Science, School of Health Sciences, Kyorin University, Miyashita-cho 476, Hachioji, Tokyo 192, Japan. 
no history of exposure to drugs or radiation, nor maternal infection during the pregnancy. At his birth, his mother and father were 31 years old and 29 years old, respectively. His birth weight was $2,550 \mathrm{~g}(-1.7 \mathrm{SD})$ and length was $46.8 \mathrm{~cm}$ $(-1.6 \mathrm{SD})$. At 5 months of age, heart murmur was heard, but it disappeared at 1.5 years of age. He sat alone at 9 months and walked alone at 19 months.

At the age of 2.5 years, he was admitted to a hospital because of short stature. On admission, his weight, height, head circumference and chest circumference were $8.0 \mathrm{~kg}(-3.5 \mathrm{SD}), 77.7 \mathrm{~cm}(-3.5 \mathrm{SD}), 45.4 \mathrm{~cm}$ and $40.5 \mathrm{~cm}$, respectively. His mental development was mildly retarded (DQ, 95). His facial features appeared to be normal (Fig. la). He did not show any physical abnormalities except undescended testes. He had a strawberry mark on his abdomen (Fig. 1b) and slightly brownish reticular hyperpigmentation with pityriatic scales on his extremities. According to his mother, the hyperpigmentation appeared after sunburning and blistering caused by sun exposure for about $30 \mathrm{~min}$ in winter, when he was 6 months old. He was then considered to have been photohypersensitive. However, at 3 years of age, quantitative data for minimal erythema dose obtained at $24 \mathrm{hr}$ post i1radiation. revealed that his skin had normal responses against ultraviolet light.

Hematological examination, urinalysis, blood chemistry and serological analysis were all normal. Growth hormone stimulation test with arginine or glucagonproparanolol showed normal responses. He also showed normal responses to LHRH and TRH tests. The results of the examinations by chest X-ray, ECG and EEG were within normal limits.
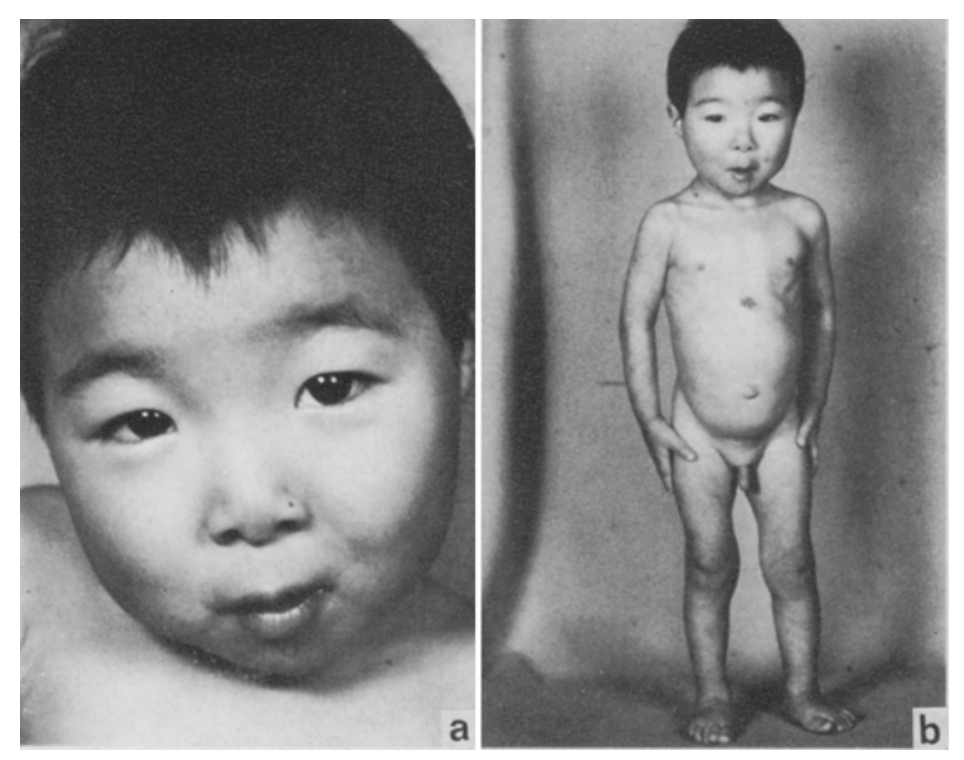

Fig. 1. a) Facies of the patient at the age of 2.5 years. b) General appearance of the patient. 


\section{CYTOGENETIC STUDIES}

The results of chromosome studies are summarized in Table 1. Chromosome analyses of PHA-stimulated lymphocytes cultured for 3 days were performed on two occasions, and demonstrated two major cell types: one with $46, \mathrm{XY}, \mathrm{r}(\mathrm{C})$ and the other with $45, \mathrm{XY},-\mathrm{C}$ karyotypes. G- and Q-band analyses clarified the affected chromosome to be a chromosome 10. Percentages of the two cell types were not significantly different in the two separate samples: approximately $85 \%$ of the cells contained a ring 10 , and most of the remainder showed 45 chromosomes lacking a No. 10. In the second sample, two of 150 cells examined were found to show a normal male karyotype. The presence of the karyotypically normal cells was further confirmed by examining the lymphoblastoid cell line (LCL) established by Epstein-Barr virus (EBV)-mediated transformation: on the 11th day after EBV infection, only one cell with a normal karyotype was found in a total of 180 cells examined, but the incidence of the normal cells increased reaching as high as $65 \%$ in the cell population after maintenance in vitro for 1.5 months. The same trend was also observed in another LCL from this patient which was established after a three months' interval (data not shown). In fibroblast cultures from a skin biopsy, both the two major cell types were observed, but no karyotypically normal cells could be detected. Q-banding analyses on the karyotypically normal cells, cells with a ring 10 and cells lacking a chromosome 10 revealed that heteromorphic regions of chromosomes 3, 13-15 and 21-22 and $Y$ were all identical among the three cell types (Fig. 2). This may exclude the latent possibility that these cell types were of different origin; i.e. chimerism or in vitro cell contamination. Thus, the patient's karyotype could be designated as $\operatorname{mos} 45, \mathrm{XY},-10 / 46, \mathrm{XY} / 46, \mathrm{XY}, \mathrm{r}(10)$.

Table 1. Chromosomal findings in PHA-stimulated peripheral blood lymphocytes, EBV-transformed lymphoblastoid cell line (LCL) and cultured skin fibroblasts.

\begin{tabular}{|c|c|c|c|c|c|c|c|}
\hline & \multirow{2}{*}{$\begin{array}{c}\text { No of } \\
\text { cells } \\
\text { obs. }\end{array}$} & \multicolumn{6}{|c|}{ Chromosome constitution } \\
\hline & & $45, \mathrm{r}^{\mathrm{a}}$ & $45,-10$ & $46, \mathrm{r}$ & $46,-10^{b}$ & 46, normal & $47, \mathrm{rr}^{\mathrm{c}}$ \\
\hline \multicolumn{8}{|c|}{ Lymphocytes cultured with PHA: } \\
\hline 1st sample & 94 & 4 & 10 & 79 & 1 & 0 & 0 \\
\hline 2nd sample & 149 & 5 & 23 & 118 & 1 & 2 & 0 \\
\hline \multicolumn{8}{|l|}{ EBV-transformed LCL: } \\
\hline 11 days in vitro & 166 & 8 & 47 & 106 & 2 & 1 & 2 \\
\hline 1.5 months in vitro & 97 & 0 & 23 & 9 & 0 & 65 & 0 \\
\hline \multicolumn{8}{|l|}{ Fibroblast cultures: } \\
\hline 5th passage & 75 & 6 & 9 & 59 & 0 & 0 & 1 \\
\hline
\end{tabular}




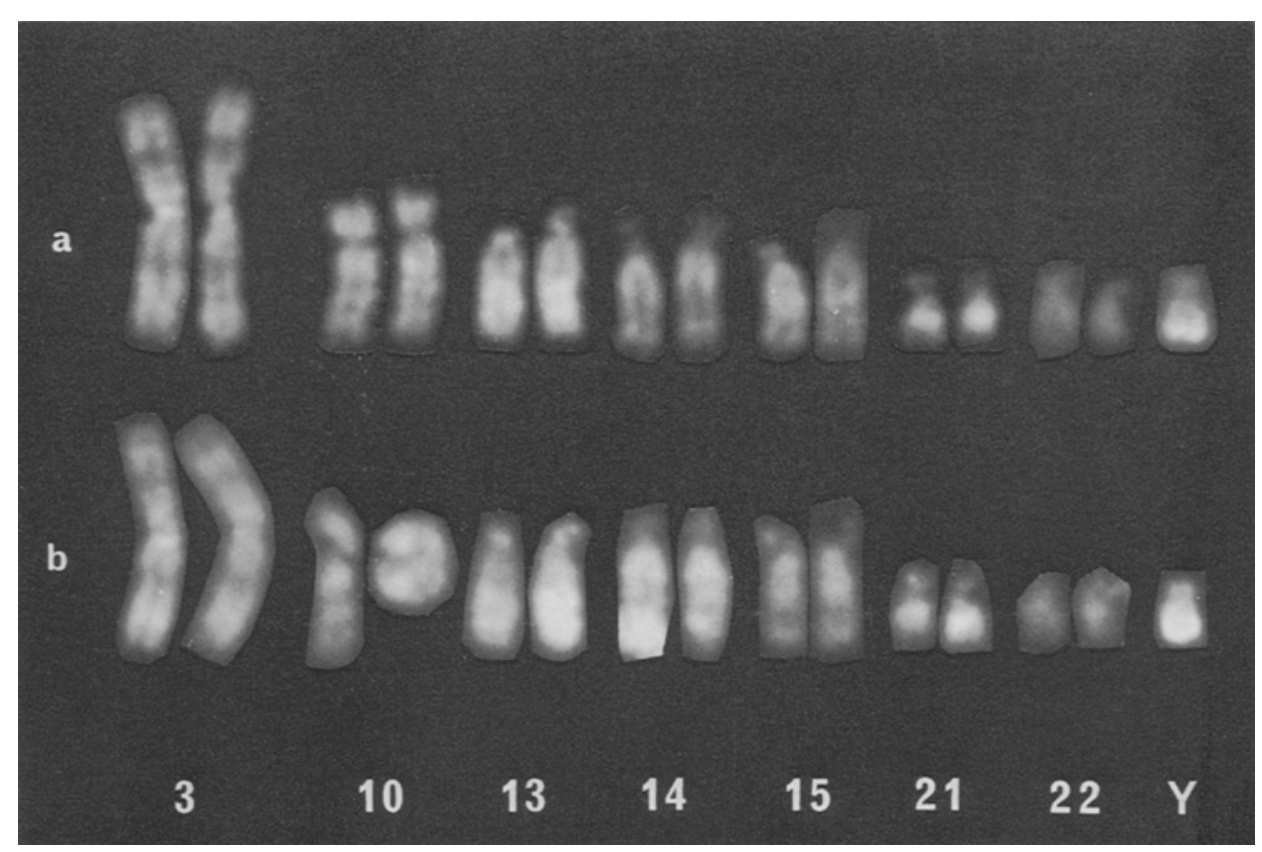

Fig. 2. Partial Q-banded karyotypes from a cell having two normal chromosomes 10 (a) and a cell with a ring $10(\mathrm{~b})$.

In order to further delineate the ring chromosome, the high-resolution G-banding analyses were made by application of the ethidium bromide pretreatment method (Ikeuchi and Sasaki, 1979; Ikeuchi, 1984) to the lymphocyte cultures. Some 20 mitotic spreads at the 550- to 850 -band stages were analyzed and a representative picture is shown in Fig. 3. It was found that the ring 10 retained all the subtle subbands usually seen at the above band stages, including subbands p15.2 and q26.2 located in the most distal regions of both arms. The breakpoints in the ring formation were thus determined as p15.3 and q26.3, respectively.

\section{DISCUSSION}

Some common clinical features of patients with a ring 10 chromosome have been delineated: these include mental and developmental retardation, short stature, microcephaly, ocular anomaly such as strabismus or cataract, low set ears, stubby nose, malformed urinary tracts and cryptorchidism in males (Michels et al., 1981; Nakai et al., 1983; Kondo et al., 1984). The present case shared some of the characteristic features, but his overall clinical picture was strikingly mild compared with the other reported patients. He showed no facial anomalies nor urinary tract malformations, the latter being one of the most specific signs associated with the ring 10 .

In general, phenotypes of patients with a ring chromosome may depend on the 


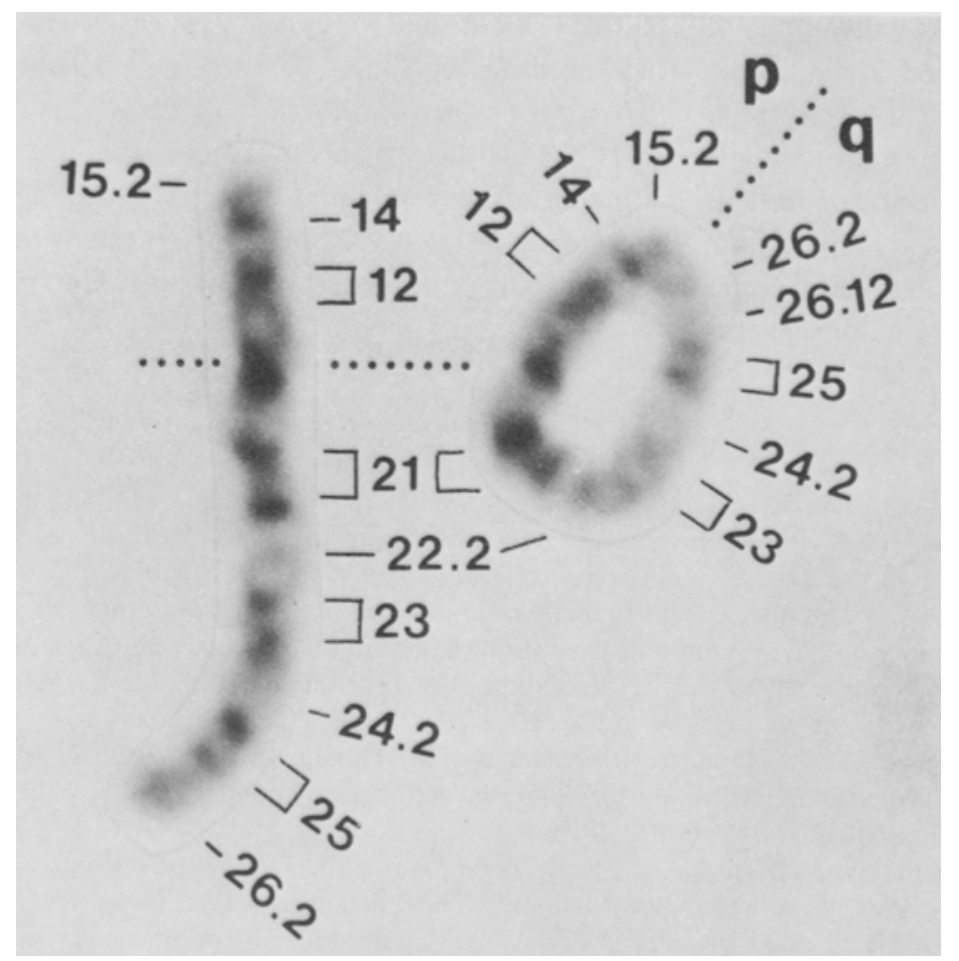

Fig. 3. High-resolution G-banded chromosomes 10. The breakpoints in the ring chromosome are within $\mathrm{p} 15.3$ and $\mathrm{q} 26.3$.

amount of deficiency in each chromosome arm and the degree of mosaicism for cells lacking the ring chromosome. In the nine reported patients with a ring 10 chromosome, terminal ends within bands $\mathrm{p} 15$ and $\mathrm{q} 26$ were thought to be deleted because the ring 10 showed an intact G- or Q-banding pattern. Most of these cases were analyzed with the routine banded metaphase chromosomes, whereas Kondo et al. (1984) examined prometaphase chromosomes at an approximately 550-band level. The high-resolution banding analyses in the present study demonstrated that the deficiency should be extremely small in size, as they were not morphologically identifiable even at the level of 850 -band stage. The degree of mosaicism in the present case was not much different from those in some other patients where more than $70 \%$ of cells had the ring 10 . Our patient is the only case in which the cells having 46 chromosomes with a normal karyotype were actually detected, indicating that the ring 10 here concerned is of postzygotic origin. The relatively mild phenotypic abnormalities in our patient might be attributed in part to the presence of these normal cells, though their incidence was quite low in short-term culture conditions. Another possible interpretation of the mild phenotype would be that the deleted 
materials in our case might be much smaller than in the other reported patients.

It seems worthy of note that our patient had an episode of photohypersensitivity and exhibited a significantly increased susceptibility to chromosome aberrations in lymphocytes after treatment in vitro with 4-nitroquinoline-1-oxide (Kishi et al., 1983). This finding might be analogous to the cellular or chromosomal response reported in cultured cells from patients with Cockayne syndrome or xeroderma pigmentosum. However, whether the finding is causally related to the ring 10 remains unclear, and further studies from comparable patients are needed to establish the possible sig. nificance of this observation.

\section{REFERENCES}

Fryns, J.P., De Boeck, K., Jaeken, J., and van den Berghe, H. 1978. Malformative syndrome associated with a ring 10 chromosome and a translocated $10 \mathrm{q} / 19$ chromosome. Hum. Genet. 43: $239-244$.

Ikeuchi, T. 1984. Inhibitory effect of ethidium bromide on mitotic chromosome condensation and its application to high-resolution chromosome banding. Cytogenet. Cell Genet. 38: 56-61.

Ikeuchi, T. and Sasaki, M. 1979. Accumulation of early mitotic cells in ethidium bromide-treated human lymphocyte culture. Proc. Jpn. Acad. 55: 15-18.

Kishi, K., Ikeuchi, T., Yamamoto, K., Tonomura, A., Tomita, M., Sakurada, N., and Satoh, Y. 1983. Chromosomal sensitivity to $4 \mathrm{NQO}$ in peripheral lymphocytes of a patient with $\mathrm{r}(10)$ (abstract). Jpn. J. Human Genet. 28: 155-156.

Kondo, I., Shimakura, Y., Hirano, T., Kaneko, M., and Yabuta, K. 1984. Ring chromosome 10 syndrome: case report and the possibility of clinical diagnosis. Clin. Genet. 25: 196-200.

Lansky, S., Daniel, W., and Fleiszar, K. 1977. Physical retardation associated with ring chromosome mosaicism: 46,XX,r(10)/45,XX,10-. J. Med. Genet. 14: 61-63.

Michels, V.V., Driscoll, D.J., Ledbetter, D.H., and Riccardi, V.M. 1981. Phenotype associated with ring 10 chromosome: report of patient and review of literature. Am. J. Med. Genet. 9: 231-237.

Nakai, H., Adachi, M., Katsushima, N., Yamazaki, N., Sakamoto, M., and Tada, K. 1983. Ring chromosome 10 and its clinical features. J. Med. Genet. 20: 142-144.

Serville, F., Briault, R., Taillemite, J.L., Despoisse, S., Cotoni, P., and Broustet, A. 1982. Chromosome 10 en anneau: 46,XX,r(10) (p15q26). Ann. Genet. 25: 168-171.

Simoni, G., Rossella, F., Dalpra, L., Visconti, G., and Piria-Schwarz, C. 1979. Ring chromosome 10 associated with multiple congenital malformations. Hum. Genet. 51: 117-121.

Sparkes, R.S., Ling, S.M., and Muller, H. 1978. Ring 10 chromosome: 46,XX,r10(p15q26). Hum. Genet. 43: 341-345.

Tsukino, R., Tsuda, N., Dezawa, T., Ishii, T., and Koike, M. 1980. Ring chromosome 10: 46,XX, r(10) (p15-q26). J. Med. Genet. 17: 148-151. 